\title{
Особенности переноса заряда в легированных слоях сульфида цинка в низкочастотном переменном электрическом поле
}

\author{
(C) В.Т. Аванесян, А.Б. Жаркой, А.В. Ракина \\ Российский государственный педагогический университет им. А.И. Герцена, \\ 191186 Санкт-Петербург, Россия \\ E-mail: avanesyan@mail.ru
}

Поступила в Редакцию 30 января 2020 г.

В окончательной редакции 10 февраля 2020 г.

Принята к публикации 10 февраля 2020 г.

Исследованы особенности поведения спектров компонентов импеданса и электрического модуля для поликристаллических слоев сульфида цинка, легированного медью. Установлена дисперсия частотных зависимостей электрофизических параметров, отвечающая распределению времен релаксации. Для интерпретации экспериментальных данных привлекается эквивалентная схема образца, включающая элемент постоянной фазы и описывающая особенности процесса электротранспорта в исследуемой поликристаллической системе.

Ключевые слова: сульфид цинка, дисперсия, релаксация, электротранспорт, импеданс, электрический модуль.

DOI: 10.21883/FTP.2020.06.49377.9361

\section{1. Введение}

Широкозонные полупроводниковые материалы группы $\mathrm{A}^{\mathrm{II}} \mathrm{B}^{\mathrm{VI}}$ нашли активное применение в качестве высокоэффективных источников света. Прикладное значение поликристаллических полупроводниковых структур на основе сульфида цинка $\mathrm{ZnS}$ обусловлено возможностью их использования в различных современных элементах оптоэлектроники, в частности, электролюминесцентных дисплеях. Указанный материал не является токсичным по сравнению с соединениями кадмия и селена и при активации примесью меди позволяет получать электролюминесцентные источники света голубого и зеленого свечения.

К недостаткам поликристаллических цинк-сульфидных электролюминофоров переменного тока можно отнести относительно невысокую яркость и стабильность свечения. Ухудшение яркости, в частности, может быть обусловлено присутствием малоэффективных ловушек значительной глубины из-за внедрения в структуру ионов кислорода, оказывающих влияние на процессы электротранспорта носителей заряда. При этом старение электролюминесцентного слоя можно связать с переносом ионов меди под действием электрического поля [1].

Проблемы улучшения цветовых и яркостных характеристик электролюминесцентных слоев, а также уменьшения скорости их старения являются актуальными и могут быть связаны с изучением электротранспорта в полупроводниковых слоях на основе системы $\mathrm{ZnS}: \mathrm{Cu}$. При этом следует учитывать возможность формирования гетеропереходов с включением твердой фазы $\mathrm{Cu}_{x} \mathrm{~S}$, где $1 \leq x \leq 2$, образующейся на поверхности электролюминофора [2].

В данной работе представлены результаты экспериментальных исследований электропроводности поли- кристаллических слоев сульфида цинка, легированного медью в переменном электрическом поле.

\section{2. Эксперимент}

Исследуемый образец представлял собой конденсаторную сандвич-структуру. На стеклянную пластину, покрытую слоем оксида индия-олова (Indium Tin Oxide или ITO), наносился слой порошкообразного, легированного медью (содержание $0.1-0.3 \%$ ) сульфида цинка (промышленный электролюминофор переменного тока Э-455) толщиной $\sim 100$ мкм. В качестве связующего материала использовался цианэтиловый эфир поливинилового спирта ЦЭПС. Роль указанного полимерного биндера, кроме выполнения функции скрепления частиц люминесцирующего слоя, защиты их от электрического пробоя и внешнего воздействия, заключалась в концентрации внутреннего электрического поля, оказывающего влияние непосредственно на зерна электролюминофора. Ранее [3] было показано, что применение ЦЭПС в качестве связующего материала в составе электролюминесцентного источника света обусловливает высокий уровень яркости излучения. Вторым электродом являлся слой аквадага - проводящего графитового покрытия марки AquaDagE. C применением прецизионного измерителя иммитанса LCR-819 определялись импедансные характеристики в частотном диапазоне $f=10$ Гц-100 кГц при амплитуде измерительного напряжения 1 В. Измерения проводились в изотермических условиях при температуре $T=293 \mathrm{~K}$.

Выявление состава сформированной структуры и присутствия в ней примеси $(\mathrm{Cu})$ проводилось методом рентгенофлуоресцентного анализа с применением энергодисперсионного спектрометра БРА-135F (рис. 1). 


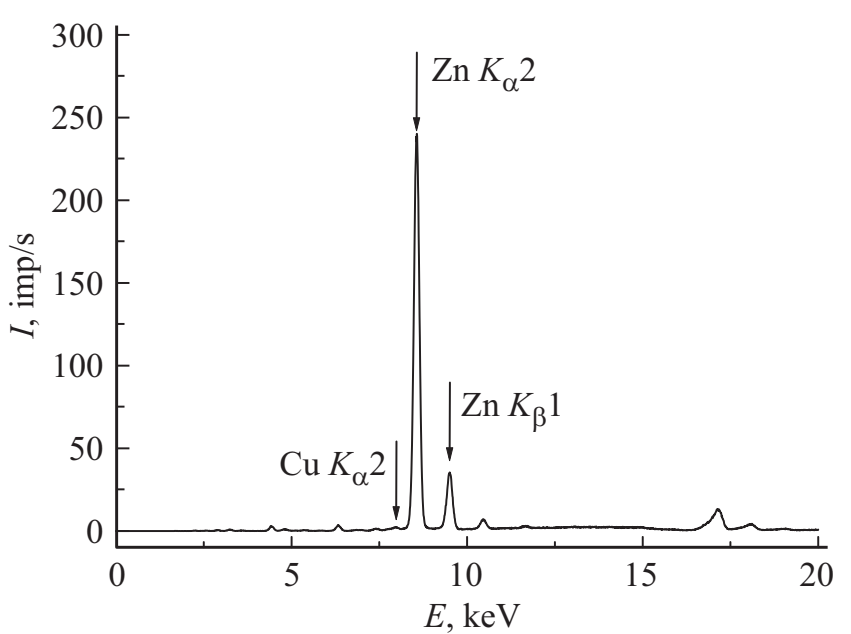

Рис. 1. Рентгенофлуоресцентный спектр слоя $\mathrm{ZnS}: \mathrm{Cu}$.

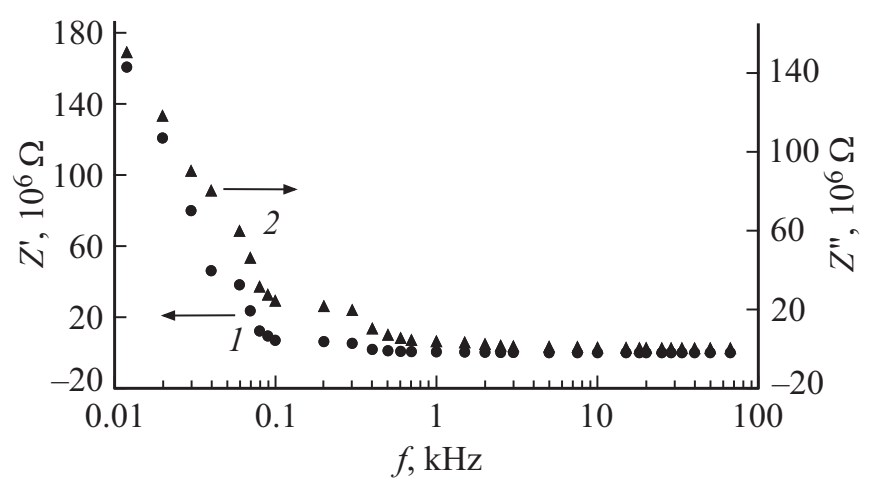

Рис. 2. Частотная зависимость действительной (1) и мнимой (2) компонент импеданса для слоя $\mathrm{ZnS}: \mathrm{Cu}$.

\section{3. Результаты экспериментов и их обсуждение}

Существенное влияние на электрофизические характеристики излучающих слоев оказывают такие процессы, как блокирование носителей заряда на электродах, формирование объемных зарядов и их релаксация, межзеренные барьеры в поликристаллической структуре и др. Как известно [4], в этом случае эффективным методом определения вклада указанных процессов в полную проводимость системы является метод импедансной спектроскопии.

На рис. 2 представлены частотные зависимости действительной $Z^{\prime}$ и мнимой $Z^{\prime \prime}$ частей импеданса образца слоя $\mathrm{ZnS}: \mathrm{Cu}$ :

$$
Z^{*}=Z^{\prime}-i Z^{\prime \prime}=1 / j \omega C_{o} \varepsilon^{*},
$$

где $\varepsilon^{*}=\varepsilon^{\prime}-i \varepsilon^{\prime \prime}-$ комплексная диэлектрическая проницаемость ( $\varepsilon^{\prime}$ и $\varepsilon^{\prime \prime}$ - действительная и мнимая компоненты $\varepsilon^{*}$ соответственно), $\omega=2 \pi f-$ угловая частота, $C_{o}$ - геометрическая емкость, определяемая как $\varepsilon_{o} S / d$ (здесь $\varepsilon_{o}$ - электрическая постоянная, $S-$ площадь, $d$ - толщина образца).
Как следует из экспериментальных результатов, полученных в отсутствие постоянного электрического смещения, в области низких частот наблюдается резкий спад функции $Z^{\prime}(f)$ в интервале $f=10-10^{2}$ Гц, а для функции $Z^{\prime \prime}(f)$ аналогичное поведение имеет место в частотной области $10-10^{3}$ Гц. Таким образом, полученные зависимости обнаруживают дисперсию, выраженную в уменьшении значений компонентов комплексного импеданса с ростом частоты электрического поля. Начиная с частоты $f>10^{3}$ Гц экспериментальные дисперсионные зависимости выходят на постоянный минимальный уровень значений.

Как следует из данных, представленных на рис. 3, годограф импеданса в данном случае представляет собой фрагмент дуги окружности с центром, лежащим ниже оси абсцисс, который переходит в прямолинейный участок, т. е. отвечает неидеальному „дебаевскому“ поведению, обусловленному распределением времен диэлектрической релаксации. Таким образом, в поликристаллических слоя $\mathrm{ZnS}$ : $\mathrm{Cu}$ имеются две области дисперсии низкочастотная и высокочастотная. Характер зависимости $Z^{\prime \prime}\left(Z^{\prime}\right)$ в области низких частот измерения указывает на возможность реализации релаксационных процессов миграционной поляризации, обусловленных диффузией и накоплением зарядов на межзеренных границах [5]. Таким образом, дополнительный вклад в проводимость может вносить перенос носителей по межкристаллитной границе.

Импедансу исследуемого образца, в простейшем случае, может соответствовать эквивалентная схема замещения, включающая две параллельные $R C$-цепи, соединенные последовательно. В этом случае учитываются импедансы, относящиеся к объему зерна и непосредственно к межзеренной границе. Различие вклада указанных составляющих в общий импеданс может отражаться на форме зависимостей $Z^{\prime \prime}\left(Z^{\prime}\right)$. Для учета разброса значений сопротивлений межзеренных границ и их емкостей целесообразно введение в рассматриваемую экви-

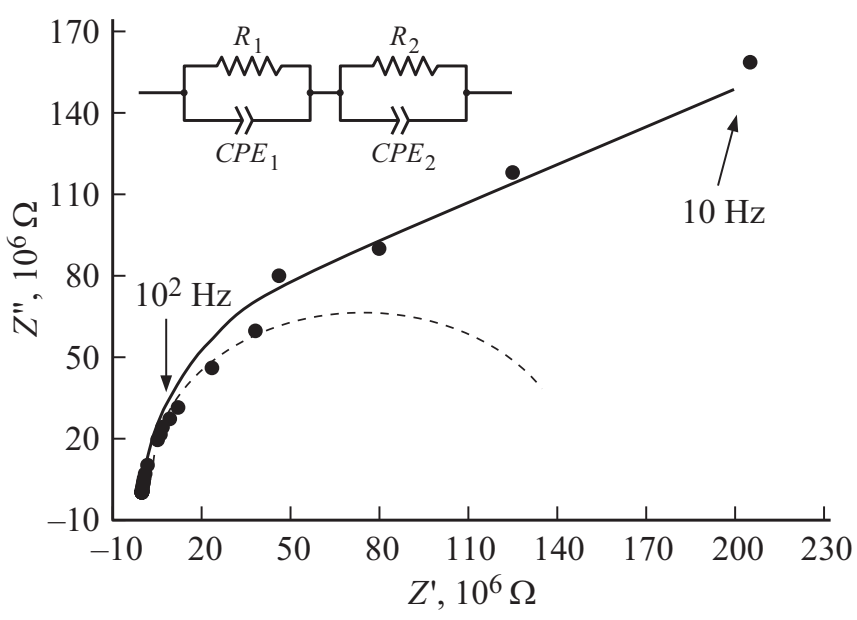

Рис. 3. Годограф импеданса для слоя $\mathrm{ZnS}: \mathrm{Cu}$. На вставке эквивалентная схема образца. 
Результат аппроксимации годографа импеданса слоя $\mathrm{ZnS}: \mathrm{Cu}$

\begin{tabular}{c|c|c|c|c|c|c|c}
\hline \multicolumn{1}{c}{ Элементы схемы и параметры } \\
\hline$R_{1}$, Ом & $A_{1}, \Phi$ & $n_{1}$ & $C_{\mathrm{CPE} 1}, \Phi$ & $R_{2}$, Ом & $A_{2}, \Phi$ & $n_{2}$ & $C_{\mathrm{CPE} 2}, \Phi$ \\
\hline 251.85 & $4.5 \cdot 10^{-4}$ & 0.75 & $2.18 \cdot 10^{-4}$ & 306.32 & $4.3 \cdot 10^{-4}$ & 0.73 & $1.74 \cdot 10^{-4}$
\end{tabular}

валентную схему элементов постоянной фазы (constant phase element) CРE [6] (см. вставку на рис. 3). Последнее связано с распределением параметров, характеризующих процесс преодоления энергетических барьеров при переносе заряда, и поведением импеданса в исследуемом диапазоне частот, обусловленным проявлением свойств фрактальности образцов. Таким образом, элементы СРЕ отражают усредненные значения сопротивлений и емкостей непосредственно зерен и границ раздела между ними. Как известно [7], импеданс элемента СРЕ задается формулой

$$
Z_{\mathrm{CPE}}^{*}=\left[A(i \omega)^{n}\right]^{-1},
$$

где $A-$ частотно-независимый множитель (фактор пропорциональности), $-1 \leq n \leq 1-$ показатель степени, определяющий характер частотной зависимости импеданса, отвечающий конкретному фазовому сдвигу и являющийся мерой искажения диаграммы $Z^{\prime \prime}\left(Z^{\prime}\right)$. Для ,дебаевского“ диэлектрика $n=1$ и элемент СРЕ представляет собой идеальный конденсатор с величиной емкости $C=A$. Если показатель $n<1$, то конденсатор является частотно-зависимым элементом. При $n=0$ CРЕ ведет себя как резистор с сопротивлением $R=1 / A$.

Для цепи, состоящей из параллельно соединенных резистора $R$ и элемента постоянной фазы, характеристическое время накопления заряда (время релаксации) отвечает выражению [8]:

$$
\tau_{o}=(R A)^{1 / n}=1 / \omega_{o},
$$

где $\omega_{o}-$ угловая частота при максимальном значении мнимой компоненты импеданса на годографе. Расчетное значение параметра $\tau_{o}$ составило $6.4 \cdot 10^{-3} \mathrm{c}$.

Определение соответствующих параметров для приведенной эквивалентной схемы проводилось с помощью специальной программы моделирования импедансных спектров EIS - Spectrum Analyzer [6]. Численные значения величин, полученные при аппроксимации экспериментального годографа импеданса, приведены в таблице. Так как значение показателя $n$ оказалось $<1$, но не равным нулю, то параметр $A$ имеет размерность $\mathrm{OM}^{-1} \cdot \mathrm{c}^{n}$.

Для наблюдаемой формы годографа $\tau_{o}$ представляет собой некоторую усредненную величину, отвечающую распределению времен релаксации [9]. Существование указанного распределения обусловлено как сложной электронной структурой интерфейсов, так и присутствием структурных и электрических неоднородностей в исследуемом материале.
В поликристаллических материалах на фоне относительно больших сопротивлений границ зерен их объемные сопротивления могут быть замаскированы. Дополнительная информация о механизмах электротранспорта может быть получена из анализа поведения комплексного электрического модуля [10]:

$$
M^{*}(\omega)=1 / \varepsilon^{*}=M^{\prime}(\omega)+i M^{\prime \prime}(\omega),
$$

где $M^{\prime}$ и $M^{\prime \prime}$ представляют собой действительную и мнимую составляющие $M^{*}$ соответственно.

Модульное представление по сравнению с импедансным, как правило, приводит к более ясной картине поляризационных явлений. При использовании формализма электрического модуля на величины его действительной и мнимой компонент в основном оказывают воздействие объемные свойства кристаллитов, а влияние межкристаллитных границ и электродов малозаметно. Компоненты $M^{*}$ могут быть определены следующим образом:

$$
\begin{aligned}
M^{\prime} & =\varepsilon^{\prime} /\left(\varepsilon^{\prime 2}+\varepsilon^{\prime \prime 2}\right), \\
M^{\prime \prime} & =\varepsilon^{\prime \prime} /\left(\varepsilon^{\prime 2}+\varepsilon^{\prime \prime 2}\right) .
\end{aligned}
$$

Значения составляющих комплексной диэлектрической проницаемости находятся расчетным путем согласно выражениям:

$$
\begin{aligned}
& \varepsilon^{\prime}=Z^{\prime \prime} /\left(2 \pi f \varepsilon_{o} S / d Z^{2}\right), \\
& \varepsilon^{\prime \prime}=Z^{\prime} /\left(2 \pi f \varepsilon_{o} S / d Z^{2}\right),
\end{aligned}
$$

где параметр $Z$ представляет собой модуль импеданca $Z^{*}$.

Как следует из изотермических частотных зависимостей, приведенных на рис. 4 , на низких частотах измерения значения действительной компоненты $M^{*}$ малы и

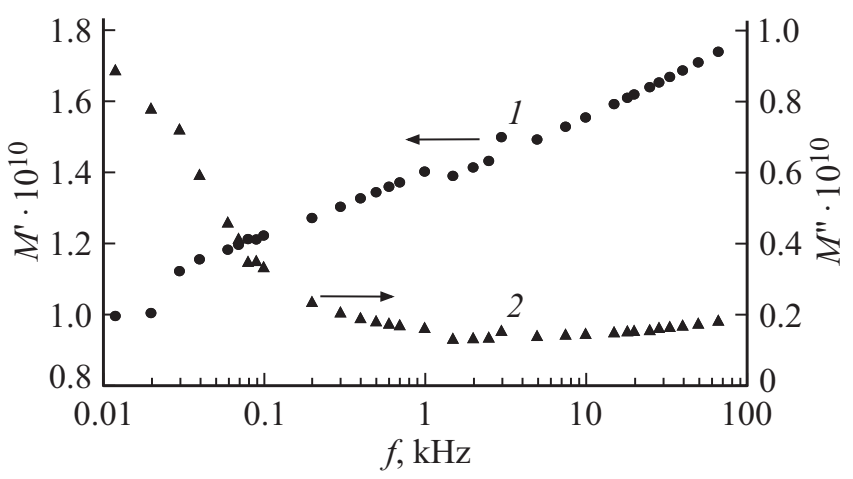

Рис. 4. Частотная зависимость действительной (1) и мнимой (2) компонент электрического модуля для слоя $\mathrm{ZnS}: \mathrm{Cu}$. 
стремятся к нулю, что может указывать на отсутствие электродной поляризации. Отсутствие максимума на зависимости $M^{\prime}(f)$ является следствием того факта, что указанный параметр определяется компонентой $\varepsilon^{\prime}$, т.е. отражает способность материала накапливать электрическую энергию. Увеличение значений параметра $M^{\prime}$ с ростом частоты может быть также связано с наличием распределения времен релаксации поляризационных процессов в исследуемом диапазоне частот.

Частотная зависимость мнимой составляющей $M^{*}$ (рис. 4) обнаруживает максимум в начальной частотной области, обусловленный вероятной релаксацией проводимости, и уменьшение значений компоненты $M^{\prime \prime}$ с ростом частоты электрического поля.

\section{4. Заключение}

Таким образом, анализ экспериментальных результатов изучения электрофизических свойств поликристаллических слоев на основе сульфида цинка, легированного медью, позволяет сделать следующие основные выводы.

Установлен недебаевский механизм диэлектрической поляризации с распределением времен релаксации. Импедансный отклик объекта исследования может характеризоваться эквивалентной схемой с включением элемента, отражающего проявление свойств фрактальности исследуемых структур в заданном диапазоне частот измерения. Анализ поведения дисперсионных зависимостей компонентов импеданса и электрического модуля указывает на вклад в процесс электропереноса объемных свойств и границ раздела зерен поликристаллической структуры емкостной природы.

\section{Конфликт интересов}

Авторы заявляют, что у них нет конфликта интересов.

\section{Список литературы}

[1] В.Т. Аванесян, А.В. Ракина, В.Г. Пак, М.М. Сычев. ФТТ, 60, 265 (2018).

[2] А.Н. Георгобиани. Соросовский образовательный журн., $6(3), 105$ (2000).

[3] В.Т. Аванесян, А.Л. Заграничек, М.К. Коршунова, Н.М. Михайловская, М.М. Сычев. Матер. VII Междунар. науч.-техн. конф. (Intermatic-2009), 223 (2009).

[4] F. Kremer, A. Schönhals. Broadband Dielectric Spectroscopy (Springer Science \& Business Media, 2010).

[5] А.М. Солодуха, 3.А. Либерман. Вестн. ВГУ, № 2, 67 (2003).

[6] Н.А. Дрокин, А.В. Федотова, Г.А. Глущенко, Г.Н. Чурилов. ФTT, 52, 607 (2010).

[7] D. Mančić, V. Paunović, M. Vijatović, B. Stojanović, Lj. Živković. Sci. Sintering, 40, 283 (2008).

[8] И.Е. Кононова, А.С. Леньшин, М.Г. Аньчков, В.А. Мошников. Изв. вузов. Матер. электрон. техн., 66, 168 (2014).

[9] A. Jonscher. J. Phys. D: Appl. Phys., 32, R57 (1999).
[10] A. Molak, M. Paluch, S. Pawlus, J. Klimontko, Z. Ujma, I. Gruszka. J. Phys. D: Appl. Phys., 38, 1450 (2005).

Редактор Г.А. Оганесян

\section{Features of charge transfer in doped layers of zinc sulphide in low frequency alternating electric field}

\author{
V.T. Avanesyan, A.B. Zarkoy, A.V. Rakina \\ Herzen State Pedagogical University of Russia, \\ 191186 St. Petersburg, Russia
}

\begin{abstract}
The features of the behavior of the spectra of the components of the impedance and the electrical module for polycrystalline layers of zinc sulfide doped with copper are studied. The dispersion of the frequency dependences of the electrophysical parameters corresponding to the distribution of relaxation times is established. To interpret the expetimental data, an equivalent circuit of the sample is involved that includes a constant phase element and describes the features of the electric transport process in the polycrystalline system under study.
\end{abstract}

